\title{
Use of satellite and modeled soil moisture data for predicting event soil loss at plot scale
}

\author{
F. Todisco ${ }^{1}$, L. Brocca ${ }^{2}$, L. F. Termite ${ }^{1}$, and W. Wagner ${ }^{3}$ \\ ${ }^{1}$ Department of Agricultural, Food and Environmental Sciences, Hydraulic and Forestry Division, University of Perugia, \\ Perugia, Italy \\ ${ }^{2}$ Research Institute for Geo-Hydrological Protection, National Research Council, Perugia, Italy \\ ${ }^{3}$ Department of Geodesy and Geoinformation, Vienna University of Technology, 10 Gusshausstr. 27-29, Vienna, Austria
}

Correspondence to: F. Todisco (francesca.todisco@unipg.it)

Received: 18 February 2015 - Published in Hydrol. Earth Syst. Sci. Discuss.: 13 March 2015

Revised: 5 August 2015 - Accepted: 24 August 2015 - Published: 11 September 2015

\begin{abstract}
The potential of coupling soil moisture and a Universal Soil Loss Equation-based (USLE-based) model for event soil loss estimation at plot scale is carefully investigated at the Masse area, in central Italy. The derived model, named Soil Moisture for Erosion (SM4E), is applied by considering the unavailability of in situ soil moisture measurements, by using the data predicted by a soil water balance model (SWBM) and derived from satellite sensors, i.e., the Advanced SCATterometer (ASCAT). The soil loss estimation accuracy is validated using in situ measurements in which event observations at plot scale are available for the period 2008-2013. The results showed that including soil moisture observations in the event rainfall-runoff erosivity factor of the USLE enhances the capability of the model to account for variations in event soil losses, the soil moisture being an effective alternative to the estimated runoff, in the prediction of the event soil loss at Masse. The agreement between observed and estimated soil losses (through SM4E) is fairly satisfactory with a determination coefficient (log-scale) equal to $\sim 0.35$ and a root mean square error (RMSE) of $\sim 2.8 \mathrm{Mg} \mathrm{ha}^{-1}$. These results are particularly significant for the operational estimation of soil losses. Indeed, currently, soil moisture is a relatively simple measurement at the field scale and remote sensing data are also widely available on a global scale. Through satellite data, there is the potential of applying the SM4E model for large-scale monitoring and quantification of the soil erosion process.
\end{abstract}

\section{Introduction}

Soil is the interface between earth, air and water and hosts most of the biosphere. As soil formation is an extremely slow process, soil can be considered essentially as a nonrenewable resource. Soil is recognized as a strategic nonrenewable resource that, in addition to the specific relevant environmental role, assumes also that of a strategic policy framework for competitiveness. Therefore, specific policies and actions designed to limit the consumption of soil are required in order to create, where possible, a barrier to stop the worrying phenomenon of progressive depletion of the resource with a consequent acceleration of erosion and geological instability. The prerequisite for the effective protection of the territory is to monitor processes at different spatial and temporal scales and use the obtained database to formulate, calibrate and validate predictive models needed to define the "risk areas" and to quantify this risk. Usually, these models must be properly calibrated and validated over the territory in which they are used, making use of databases and studies carried out on a local scale (Bagarello et al., 2011, 2014; Butzen et al., 2014; Cerdà, 1998; Di Stefano et al., 2005; Kinnell, 2010; Leh et al., 2013; Morgan and Nearing, 2000; Porto et al., 2014; Vrieling et al., 2014).

Regarding soil erosion, the Universal Soil Loss Equation, USLE (Wischmeier and Smith, 1978) is the most used empirical model for the estimation of the long-term average annual soil loss of a plot associated with sheet and rill erosion. The USLE estimates the soil loss using six factors that are associated with climate, soil, topography, vegetation and soil 
management. The USLE is considered the best compromise between applicability in terms of required input data and reliability of the soil loss estimates (Risse et al., 1993). It was originally formulated to estimate the soil loss in rural areas of the USA, and then extended in the Revised USLE, RUSLE (Renard et al., 1997) and further modifications (RUSLE1, RUSLE2, Foster et al., 2003). The RUSLE conserves the same mathematical structure of the USLE, the revision being limited to the estimating procedure of some of the involved factors. Currently, the USLE/RUSLE is widely applied in Europe and in many other Mediterranean countries for practical purposes (e.g., Larson et al., 1997; Huang, 1998; Rejman et al., 1999; Bagarello and Ferro, 2004; Morgan, 2005; Parsons et al., 2006; Bagarello et al., 2008, 2010, 2011, 2012; Ligonja and Shrestha, 2013). The process-based models characterized by low computational efforts fail to produce better results than the USLE/RUSLE model (Tiwari et al., 2000). Consequently the USLE/RUSLE model is often used for purposes for which it was not designed (Kinnell, 2010). In particular, it is widely used in watershed models even at the event temporal scale. However, it was found in the scientific literature (Todisco et al., 2009; Bagarello et al., 2008; Risse et al., 1993) that the USLE/RUSLE model, and similarly (Tiwari et al., 2000) process-oriented models (e.g., Water Erosion Prediction Project, WEEP, Flanagan et al., 1995), tends to overestimate (underestimate) soil losses for low (high) erosive events. Foster et al. (1982) noted that the USLE model is somewhat unsatisfactory for estimating soil loss from individual storms, and observed that including rainfall amount, rainfall intensity and runoff amount in the erosivity factor provided better performance. Foster et al. (1982) also noted that erosivity factors with separate terms for rainfall and runoff erosivity were more appropriate. Successively, Kinnell (1997) suggested that the sediment concentration for individual rainfall event is dependent on the event rainfall erosivity index per unit rainfall depth and developed the so-called USLE-M model, including direct measures of the runoff in the event rainfall-runoff erosivity factor (Kinnell and Risse, 1998; Kinnell, 2007, 2010; Bagarello et al., 2011). Bagarello et al. (2010), by using soil loss and runoff data for a relatively high number of simultaneously operating plots of different length (11-44 m) established at the experimental station of Sparacia in southern Italy (clay soil), developed a modified version of the USLE-M, named USLE-MM, in which the event rainfall-runoff erosivity factor is raised to a power greater than 1. The USLE-MM was found to perform better than both the USLE and the USLEM at Sparacia site (Bagarello et al., 2008, 2010, 2014), and it was also successfully applied at the Masse station in central Italy, silty-clay-loam soil (Todisco et al., 2009; Bagarello et al., 2013).

Even if including runoff in the USLE/RUSLE model improves its accuracy, it should be highlighted that the measurement of the event runoff is not straightforward. At experimental stations, the surface runoff is generally collected into specific storage tanks allowing the estimation of the event runoff by measuring the amount of water in the tanks after the end of each rainfall event (Todisco et al., 2012a)

However, this procedure is time consuming and expensive, and it requires specific measurement campaigns. Otherwise, the water amount collected in the tanks could be measured by hydrometric gauges that, unfortunately, require strong maintenance and are not easy to be realized. It should be also underlined that by using the measured runoff, the same quantity (runoff) is used both for estimating the event soil losses (given by the product of runoff and the bulk sediment concentration in the tanks) and in the rainfall-runoff erosivity factor thus introducing a conceptual issue in the model determination procedure.

In the absence of direct measurements, runoff can be estimated through rainfall-runoff modeling. This usually needs a specific calibration of the parameters (and structure) to provide satisfactory results which are not easily applied at the plot scale. Therefore, notwithstanding the USLE-M and USLE-MM models have a noticeable practical interest, these models are difficult to be applied over large areas mainly for the need to also predict event runoff (Bagarello et al., 2014). The same issue can be found in other existing USLE-derived models, such as MUSLE (Williams, 1975; Williams and Berndt, 1977), EPIC (Williams et al., 1984a,b) and APEX (Williams et al., 2008), which explicitly consider the runoff characteristics, even with a certain detail, for the estimation of soil losses. Efforts have been recently made in order to incorporate reliable and parsimonious methods for the runoff estimation in the USLE-derived models. However, it is evident that a poor estimation of event runoff will produce a low-accuracy forecast of the soil loss. Gao et al. (2012) coupled a modified SCS-CN (Soil Conservation Service curve number) and RUSLE model for runoff and soil loss simulation at plot scale in the Loess Plateau. In RUSLE2, runoff prediction for storm events is obtained using the SCS-CN method with empirical equations that vary the values of $\mathrm{CN}$ in association with both soil moisture and rainfall intensity (Kinnell, 2014). Todisco et al. (2012b) evaluated the efficiency of the MISDc model (Modello idrologico semidistribuito in continuo, Brocca et al., 2011a), coupled with an USLE-derived model, for the estimation of surface runoff and soil loss at the event timescale at Masse experimental station. The model performance is found to be promising, but it was underlined that the antecedent soil moisture proved to be a good alternative with respect to runoff for correcting the rainfall-runoff erosivity factor in the USLE-MM model. These preliminary results open interesting scenarios for improving the capability of USLE-derived models in predicting the unit soil loss at the event scale. Indeed, measuring in situ soil moisture is much easier (e.g., by using Time Domain Reflectometry, Brocca et al., 2014a) and less expensive than estimating surface runoff. Moreover, the recent widespread availability of satellite-derived soil moisture data (e.g., Wagner et al., 2013) might allow one to easily apply over large 
Table 1. Summary statistics of the $22 \mathrm{~m}$ long plot data available at the Masse site.

\begin{tabular}{|c|c|c|c|c|c|c|c|c|c|c|c|c|}
\hline \multirow[t]{2}{*}{ Plot size } & \multirow[t]{2}{*}{$s$} & \multirow[t]{2}{*}{$L S$} & \multirow[t]{2}{*}{$N_{\mathrm{e}}$} & \multicolumn{2}{|c|}{$h_{\mathrm{e}}$} & \multicolumn{2}{|c|}{$R_{\mathrm{e}}$} & \multirow[t]{2}{*}{$N_{\mathrm{m}}$} & \multicolumn{2}{|c|}{$Q_{\mathrm{e}, i}$} & \multicolumn{2}{|c|}{$A_{\mathrm{e}, i}$} \\
\hline & & & & $\mu$ & $\mathrm{CV}$ & $\mu$ & $\mathrm{CV}$ & & $\mu$ & $\mathrm{CV}$ & $\mu$ & $\mathrm{CV}$ \\
\hline $22 \times 8$ & 16 & 2.04 & 62 & 35.4 & 65.2 & 81.8 & 102.6 & 113 & 3.6 & 136.6 & 4.1 & 221.5 \\
\hline $22 \times 4$ & 16 & 2.04 & 53 & 33.2 & 66.6 & 75.1 & 110.0 & 98 & 2.4 & 145.7 & 2.8 & 260.7 \\
\hline
\end{tabular}

areas a modified USLE/RUSLE model incorporating this information. In summary, it could be highly beneficial to find a procedure for incorporating soil moisture in the erosivity factor rather than runoff coefficient as in previous investigations (e.g., Kinnell, 2010; Bagarello et al., 2014).

The main objective of this study is to investigate the use of satellite-derived and modeled soil moisture data for improving the prediction of unit soil loss through a modification of USLE-based models. Specifically, it is expected that modeled soil moisture data will provide better performance, but they require continuous meteorological observations not always available. Satellite data, even though with an expected lower accuracy, have the enormous advantage of being available on a global scale, thus allowing model application everywhere. The Masse experimental area (Umbria, central Italy) is used as a case study in which rainfall, air temperature, soil losses and runoff are measured at the event timescale for different bare plots in the period 2008-2013. The satellite soil moisture product is obtained from the Advanced SCATterometer (ASCAT) through the TUWien algorithm (Wagner et al., 2013). Moreover, modeled soil moisture data obtained from the soil water balance model (SWBM) developed by Brocca et al. (2014b) are also considered. The specific objective of this study is to evaluate the opportunity of coupling soil moisture and rainfall data for correcting the erosivity index of the USLE model. For comparison, the results are evaluated against those obtained by the standard USLE/RUSLE and USLE-M-based models in previous investigations (Todisco et al., 2012b).

\section{Materials}

\subsection{The Masse experimental station and the soil loss database}

The Masse experimental station for soil erosion measurements (Fig. 1) of the Department of Agricultural, Food and Environmental Sciences, Perugia University, is located $20 \mathrm{~km}$ south of Perugia, in the region of Umbria (central Italy).

The soil is Typic Haplustept (Soil Survey Staff, 2006) with a silty-clay-loam texture (clay $=34 \%$, silt $=59 \%$ and

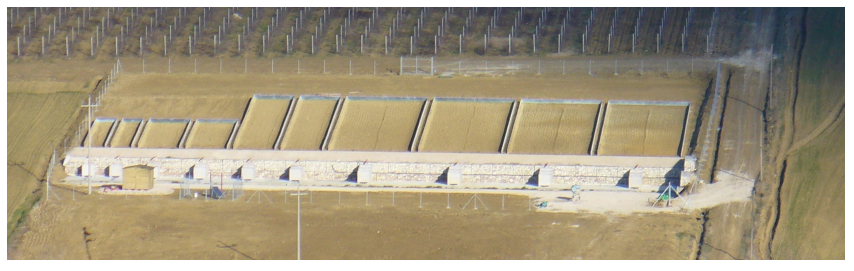

Figure 1. View of the Masse experimental station for monitoring water soil loss at plot scale in Umbria (central Italy).

sand $=7 \%$ ). The soil has a polyhedral angle structure and the gravel content is negligible. The Ap horizon has a depth of approximately $0.40 \mathrm{~m}$. The meteorological data are monitored by a weather station located within the experimental site and are recorded at a time resolution of $5 \mathrm{~min}$. The station includes plots of different length $\lambda=11$ and $22 \mathrm{~m}$ and width $w=2,4$ and $8 \mathrm{~m}$. All plots are oriented parallel to a $16 \%$ slope and are maintained in a cultivated fallow by obliterating the rills at the end of each erosive event. The total runoff amount and the soil loss per unit area are measured in each plot after an erosive event, defined as an event yielding a measurable soil loss. The Masse database was therefore developed by considering, for each event, the simultaneous measurements of plot runoff, $Q_{\mathrm{e}, i}$, and soil loss, $A_{\mathrm{e}, i}$, and of the rainfall data required to derive the erosivity factor, $R_{\mathrm{e}}$, according to Wischmeier and Smith (1978), with a mean interval time of $6 \mathrm{~h}$ (Bagarello and Ferro, 2004; Mannocchi et al., 2008; Todisco, 2014). The study area and the experimental schemes, installations and procedures are already described more in depth in Bagarello et al. (2011) and Todisco et al. (2012a).

For the purposes of this investigation, only the data collected on the $\lambda=22 \mathrm{~m}$ plots (two plots with $w=4 \mathrm{~m}$ and two plots with $w=8 \mathrm{~m}$ ) were considered. A total of 63 erosive events were monitored in the years from 2008 to 2013. Over $70 \%$ of them (45 events) occurred during the wet period (from October to May). In the $22 \mathrm{~m} \times 8 \mathrm{~m}$ experimental schemes, 62 events yielded a measurable runoff, corresponding to 113 plot measurements. In the $22 \mathrm{~m} \times 4 \mathrm{~m}$ schemes, 58 events were erosive, corresponding to 98 plot measurements. The plot data used in this investigation are summarized in Table 1. 


\subsection{Soil moisture from satellite data}

The satellite soil moisture product adopted in this study was obtained from the ASCAT radar scatterometer onboard the Metop satellites. ASCAT measures radar backscatter at the C-band $(5.255 \mathrm{GHz})$ in VV polarization. Specifically, the product delivered through the "Satellite Application Facility on Support to Operational Hydrology and Water Management (H-SAF)" project is used. Global coverage over Europe is achieved in $\sim 1.5$ days, while in Italy measurements are available about once a day. The spatial resolution of the soil moisture product is $25 \mathrm{~km}$ with a sampling distance of $12.5 \mathrm{~km}$. The surface soil moisture product is calculated from the backscatter measurements through a time-series-based change detection approach (Wagner et al., 1999, 2013). The soil moisture product obtained is expressed in terms of degree of saturation, from $0 \%$ (dry) and $100 \%$ (wet). The product obtained provides knowledge of soil moisture for a very thin surface layer (about $2 \mathrm{~cm}$ ), whereas a root-zone soil moisture product would be required for the prediction of soil losses. Even though an exact quantification of the depth of the root zone is not possible, in this study we considered that a layer depth of $15 \mathrm{~cm}$ is required. Therefore, the Soil Water Index (SWI) method (Wagner et al., 1999) was employed to convert surface soil moisture observations into a root-zone soil moisture product (i.e., the SWI). This method relies on the estimation of a single parameter, the characteristic time length, $T$, that was obtained by calibration. The reader is referred to Wagner et al. (1999) for more details on the SWI approach. Lastly, the data were converted in volumetric units $\left(\mathrm{m}^{3} \mathrm{~m}^{-3}\right)$ through a linear rescaling approach (Brocca et al., 2011b) for matching the range of variability of satellite and modeled soil moisture data provided by the SWBM. The ASCAT data for the pixel closest to the Masse study area were used.

The ASCAT soil moisture product was already validated in central Italy through the comparison with in situ observations by Brocca et al. (2010, 2011b). The obtained accuracy (RMSE) was found to range between 0.03 and $0.07 \mathrm{~m}^{3} \mathrm{~m}^{-3}$.

\section{Methods}

\subsection{Soil Moisture for Erosion model}

A USLE-derived model to predict the unit event soil loss was formulated, parameterized and tested with the use of soil moisture in the rainfall-runoff erosivity factor. The model was derived from the USLE:

$A=R \cdot K \cdot L \cdot S \cdot C \cdot P$,

where $A$ is the mean annual soil loss $\left(\mathrm{Mg} \mathrm{ha}^{-1} \mathrm{yr}^{-1}\right)$ over the long term (e.g., 20 years), $R$ ( $\mathrm{MJ} \mathrm{mm} \mathrm{ha}{ }^{-1} \mathrm{~h}^{-1} \mathrm{yr}^{-1}$ ) is the rainfall-runoff erosivity factor, and $K\left(\mathrm{Mg} \mathrm{h} \mathrm{MJ}^{-1} \mathrm{~mm}^{-1}\right)$ is the soil erodibility factor. $L$ and $S$ are the topographic factors depending on the slope length and gradient, $C$ is the crop management factor, and $P$ is the soil conservation practice factor. $L, S, C$, and $P$ are dimensionless factors. Equation (1) with the erosivity factor calculated for the single erosive event, $R_{\mathrm{e}}\left(\mathrm{MJ} \mathrm{mm} \mathrm{ha}{ }^{-1} \mathrm{~h}^{-1}\right.$ ), is also used to determine the plot soil loss at the event temporal scale, $A_{\mathrm{e}}\left(\mathrm{Mg} \mathrm{ha}^{-1}\right)$, and the corresponding unit value, $A_{u \mathrm{e}}$, as follows:

$A_{u \mathrm{e}}=\frac{A_{\mathrm{e}}}{L \cdot S \cdot C \cdot P}=R_{\mathrm{e}} \cdot K$.

Equation (2) estimates the average event soil losses fairly well, but it tends to overestimate the lowest and underestimate the highest values (Kinnell, 2010). The reason for this is found in the lack of explicit consideration of runoff. Indeed, although the rainfall erosivity and the soil erodibility are responsible for the detachment of soil particles, it is the runoff that transports the detached particles causing the soil loss. Therefore the USLE model has been further modified to account for the relationship between soil loss and runoff. Two well-known examples are the USLE-M (Kinnell and Risse, 1998) and the USLE-MM (Bagarello et al., 2008) models, in which the event rainfall-runoff erosivity factor is given by the product of $R_{\mathrm{e}}$ and the runoff coefficient $Q_{\mathrm{r}}=Q_{\mathrm{e}} / h_{\mathrm{e}}$, with $Q_{\mathrm{e}}(\mathrm{mm})$ being the event runoff and $h_{\mathrm{e}}(\mathrm{mm})$ the rainfall depth, as follows:

$A_{u \mathrm{e}}=K_{u} \cdot\left(Q_{\mathrm{r}} \cdot R_{\mathrm{e}}\right)^{\alpha}$

with $\alpha=1$ in the USLE-M and $\alpha>1$ in the USLE-MM and where $K_{u}$ varies in accordance with the selected model.

In this study, the Eq. (3) was modified using soil moisture, $\theta$, in place of the runoff coefficient, $Q_{\mathrm{r}}$, in the rainfall-runoff erosivity factor. The following model was finally formulated and named Soil Moisture for Erosion (SM4E) model:

$A_{u \mathrm{e}}=K_{u \theta} \cdot\left(\theta \cdot R_{\mathrm{e}}\right)^{\alpha}$.

With $\alpha=1$, the SM4E model is linear; that is, $A_{u \mathrm{e}}$ increases linearly with the erosivity factor corrected with the soil water content, $\theta \cdot R_{\mathrm{e}}$. With $\alpha>1$, the SM4E model is a power law; that is, the $A_{u \mathrm{e}}$, is proportional to the power of $\theta \cdot R_{\mathrm{e}}$.

Equation (4) was parameterized and tested using soil moisture data estimated by a soil water balance model (SWBM), $\theta=\theta_{\text {est }}$, and derived from satellite observations $\theta=\theta_{\text {sat }}$.

\subsection{Soil water balance model}

The soil water balance model (SWBM, Brocca et al., 2008, 2014b) was used to estimate the temporal evolution of soil moisture from standard meteorological data. SWBM considers the surface soil layer as a spatially lumped system, for which the continuous time variation of soil moisture is derived from the application of the soil water balance equation, taking into account the infiltration, evapotranspiration and drainage processes. The infiltration rate is estimated using the Green-Ampt equation. The empirical relation of Blaney and Criddle, as modified by Doorenbos and Pruitt (1977), 
is used to determine the potential evapotranspiration, from which the evapotranspiration rate is computed. The drainage rate is derived with the relation proposed by Famiglietti and Wood (1994). The model requires rainfall and air temperature data as input and incorporates five parameters that are optimized as described later in the paper. Further details on SWBM, with the full list of equations, are given in Brocca et al. (2014b).

The soil water balance model was extensively validated with actual soil moisture measurements in different studies already published in the scientific literature (Brocca et al., 2008, 2013, 2014b; Lacava et al., 2012). Specifically, in Brocca et al. (2013) the model was validated exactly in the same study area by obtaining reliable and satisfactory results. Based on previous studies, the accuracy (RMSE) of SWBM was found to range between 0.02 and $0.04 \mathrm{~m}^{3} \mathrm{~m}^{-3}$ when compared with in situ measurements. On this basis, we believe the soil water balance model is an appropriate tool for obtaining reliable soil moisture estimates.

\subsection{Calibration and testing}

The SM4E model, Eq. (4), and the SWBM model require calibration. The measured soil loss data at the different plots of the Masse experimental station were used for this purpose. Specifically, only the $22 \mathrm{~m}$ long plots were considered. The average value of the unit soil loss, $A_{u \mathrm{e}}$, was then computed by using Eq. (2) in which, specifically, $A_{\mathrm{e}}$ is the mean of the plot measures; $C$ and $P$ equal values that are assumed equal to 1 as bare plots were used; the topographic factors, $L$ and $S$, were calculated (see Table 1) according to the relations proposed by Wischmeier and Smith (1978), Eq. (5) and by Nearing (1997), Eq. (6).

$L=\left(\frac{\lambda}{22.13}\right)^{m}$

where $\lambda(m)$ is the plot length and $m$ is an exponent. In the USLE, $m$ is equal to 0.5 if slope steepness, $s$, is greater than or equal to $5 \%$.

$S=-1.5+\frac{17}{1+\exp (2.3-6.1 \sin \beta)}$,

where $\beta$ is the slope angle.

For the analysis, the database of erosive events was split to define a calibration and a validation set of events: the 63 events were arranged in descending order with respect to the $A_{u \mathrm{e}}$ values and alternatively assigned to the calibration ( $n=32$ events) or the validation set ( $m=31$ events). The calibration set was used to optimize the five parameters of the SWBM, the characteristic time length of the SWI method, and the two coefficients ( $K_{u \theta}$ and $\left.\alpha\right)$ of the SM4E models. The parameters were defined maximizing the coefficient of determination $R^{2}$, of the regression between the measured $A_{u \mathrm{e}}$ and the erosivity factor $\theta \cdot R_{\mathrm{e}}$, with $\theta=\theta_{\mathrm{est}}$ and $\theta=\theta_{\mathrm{sat}}$.
For the power model $(\alpha>1), R^{2}$ is computed by a linear regression on a logarithmic scale, while for the linear model $(\alpha=1)$, as the regression line is forced to pass through the origin, $R^{2}$ is computed on a linear scale as

$R^{2}=1-\frac{\sum_{j=1}^{n}\left(A_{u \mathrm{e}, j}-A_{u \mathrm{e}, \mathrm{est}, j}\right)^{2}}{\sum_{j=1}^{n}\left(A_{u \mathrm{e}, j}\right)^{2}}$,

where $A_{u \mathrm{e}, \mathrm{est}, j}$ is the estimated value of $A_{u \mathrm{e}}$ for the $j$ th erosive event (i.e., the soil loss that would result from the regression models), and $n$ is the number of erosive events in the calibration subset. The validation set was used to test the accuracy and robustness of the regression models SM4E, which was evaluated by the RMSE between the measured and the estimated $A_{u \text { e values. }}$

The effectiveness of the event soil loss models was also compared with that of the USLE-derived models with a simulated runoff coefficient in the erosivity factor (Kinnell, 2015; Todisco et al., 2012b). In particular Todisco et al. (2012b) coupled the USLE models with a continuous rainfall-runoff model, MISDc (Brocca et al., 2011a), for the estimation of the runoff volumes. MISDc incorporates a limited number of parameters and it is characterized by low computational efforts. The input data required are only rainfall and air temperature. Besides runoff, the model simulates also the temporal evolution of soil moisture.

In this paper, the analysis performed in Todisco et al. (2012b) was extended to the current 63 erosive events. The MISDc model was parameterized, maximizing the NashSutcliffe efficiency index between the estimates $Q_{\mathrm{e}, \text { est }}$ and the corresponding observed $Q_{\mathrm{e}}$ values of the set of calibration events. A regression analysis was also performed between the observed $A_{u \mathrm{e}}$ and the erosivity indices $R_{\mathrm{e}}, Q_{\mathrm{r} \text {,est }}$. $R_{\mathrm{e}}$ and $\left(Q_{\mathrm{r} \text {,est }} \cdot R_{\mathrm{e}}\right)^{\alpha}$. The accuracy of the regression models in soil loss estimation was evaluated by RMSE between the estimates $\left(A_{u \mathrm{e}, \mathrm{est}}\right)$ and the measurements $\left(A_{u \mathrm{e}}\right)$ of the set of validation events.

\section{Results and discussion}

\subsection{Soil moisture estimation through modeled and satellite data}

Based on the procedure mentioned above, the parameter values of the SWBM and of the SM4E models were obtained by maximizing the $R^{2}$ value between the observed and estimated $A_{u \mathrm{e}}$ values in the calibration events. Figure 2 shows the temporal evolution of the modeled and satellite soil moisture data at the beginning of the 63 erosive events that occurred during the 2008-2013 study period.

Even though the parameters of the SWBM and of the SWI method were calibrated for reproducing soil losses, and not 


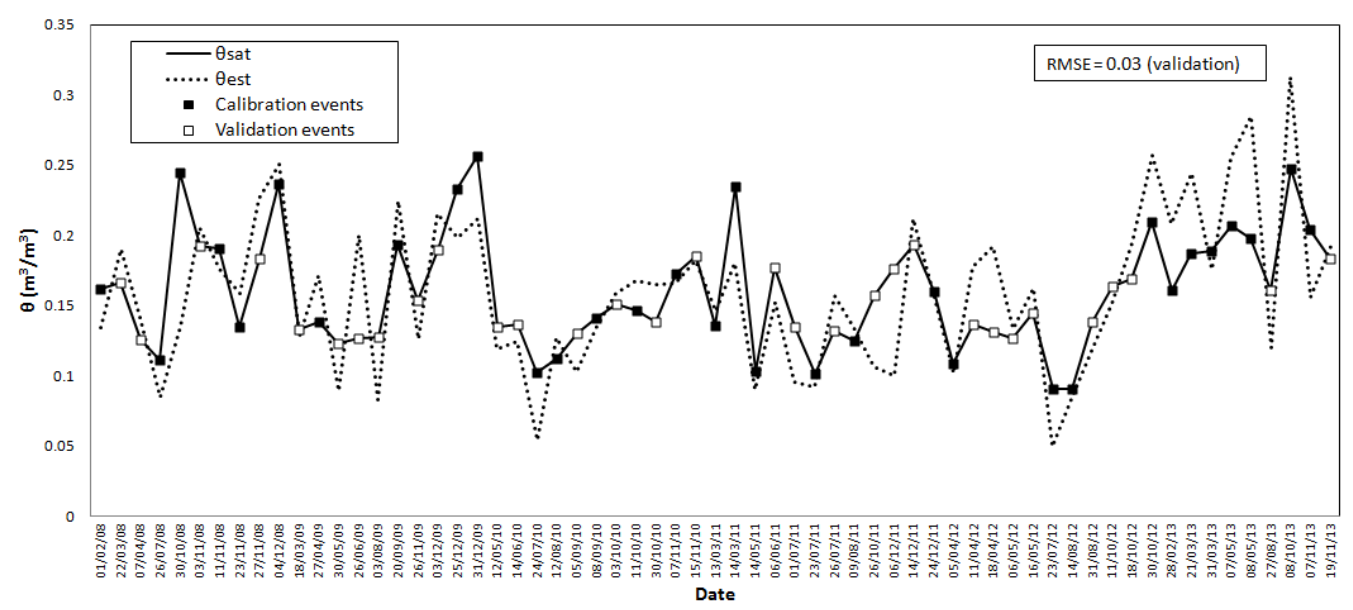

Figure 2. Time series of satellite-derived and estimated (through the SWBM) soil moisture at the beginning of 63 erosive events in the study period 2008-2013.

for making the two soil moisture data sets match each other, a very good agreement among the soil moisture time series is evident. Indeed, a very low RMSE $=0.03 \mathrm{~m}^{3} \mathrm{~m}^{-3}$ was obtained, even for the validation sets. These results confirm the capability of the ASCAT-derived soil moisture product to provide high-quality measurements in central Italy (Brocca et al., 2010, 2011b), even though the spatial mismatch between satellite and ground data is significant. As has already been shown in the scientific literature, these unexpected good results must be attributed to the statistical properties of soil moisture spatial patterns. Indeed, the temporal dynamics of soil moisture field is often very similar across a wide range of scales - a phenomenon usually referred to as "temporal stability" (e.g., Brocca et al., 2011b, 2014a). Therefore, local point measurements can be used for obtaining an estimate of soil moisture over large areas (Brocca et al., 2009) and, vice versa, coarse-scale soil moisture measurements can be properly used for small-scale applications (Brocca et al., 2012).

\subsection{Estimation of SM4E model parameters}

The scatterplots in Fig. 3 show the regressions between the soil loss and the erosivity factor $\theta R_{\mathrm{e}}$ with $\alpha \geq 1$ both with $\theta=\theta_{\text {sat }}$ (Fig. 3a and d) and $\theta=\theta_{\text {est }}$ (Fig. 3b and e) for the set of calibration events. The linear SM4E models $(\alpha=1)$ are very similar in the scale factors $K_{u, \theta}=0.178$ and 0.180 . The coefficient of determination using satellite soil moisture data $\theta=\theta_{\text {sat }}, R^{2}=0.358$, is higher than that obtained with the simulated soil moisture data $\theta=\theta_{\mathrm{est}}, R^{2}=0.325$. Also the power SM4E models are similar both in the scale factors equal to 0.007 and 0.006 , and in the exponent $\alpha$ equal to 1.69 and 1.77 for the modeled and satellite data, respectively. The coefficient of determination is slightly higher for the $\theta=\theta_{\text {est }}$ $\left(R^{2}=0.501\right)$, than for $\theta=\theta_{\text {sat }}\left(R^{2}=0.462\right)$, and in any case much higher than the linear models. The parameters for the SM4E models are given in Table 2 (all the events). The white dots in Fig. 3 represent the events that occurred during the dry period (from June to September), which will be commented on later in the paper. The erosivity index $\theta R_{\mathrm{e}}$ performs better when raised at an exponent $\alpha>1$, making it possible to obtain higher coefficients of determination $R^{2}$.

\subsection{Soil losses estimated by SM4E models}

The calibrated SM4E models were then tested with the validation set to estimate the soil loss, $A_{u \text { e,est }}$, by using the corresponding satellite soil moisture retrievals, $\theta=\theta_{\text {sat }}$, or the modeled ones, $\theta=\theta_{\text {est }}$, and event rainfall data. The results are given in Fig. 4, by showing the dispersion of the $\left(A_{u \mathrm{e}}, A_{u \mathrm{e}, \text { est }}\right)$ pairs around the $1: 1$ line for the linear model (Fig. 4a and b) and the power model (Fig. 4d and e). The results in terms of RMSE are derived and given in Table 2 (all the events). With satellite soil moisture, $\theta=$ $\theta_{\text {sat }}$, the RMSE obtained with the linear SM4E model is equal to $3.07 \mathrm{Mg} \mathrm{ha}^{-1}\left(R^{2}=0.329\right)$ and decreases slightly to $\mathrm{RMSE}=3.04 \mathrm{Mgha}^{-1}\left(R^{2}=0.371\right)$ when the power model is used. The errors decrease, even if not substantially, using estimated soil moisture $\theta=\theta_{\text {est }}$, with RMSE $=2.85 \mathrm{Mg} \mathrm{ha}^{-1}$ $\left(R^{2}=0.401\right)$ and $\mathrm{RMSE}=2.80 \mathrm{Mg} \mathrm{ha}^{-1}\left(R^{2}=0.338\right)$ with linear and power models respectively. The better performance of SM4E when using modeled data is due to the expected better accuracy of SWBM $\left(\sim 0.03 \mathrm{~m}^{3} \mathrm{~m}^{-3}\right)$ with respect to satellite data $\left(\sim 0.05 \mathrm{~m}^{3} \mathrm{~m}^{-3}\right)$.

Moreover, the linear and the power models are compared in terms of confidence intervals of the regression coefficients. The uncertainty is estimated as the percentage of the size of the $90 \%$ confidence interval with regard to the corresponding coefficient value. The results show that the uncertainty in the estimation of coefficients is similar (100\%). This result is expected, given that the data set used is the same. The lowest uncertainty $(60 \%)$ is estimated for the exponent of the power model when the erosivity factor $\left(\theta R_{\mathrm{e}}\right)^{\alpha}$ is used. Fur- 


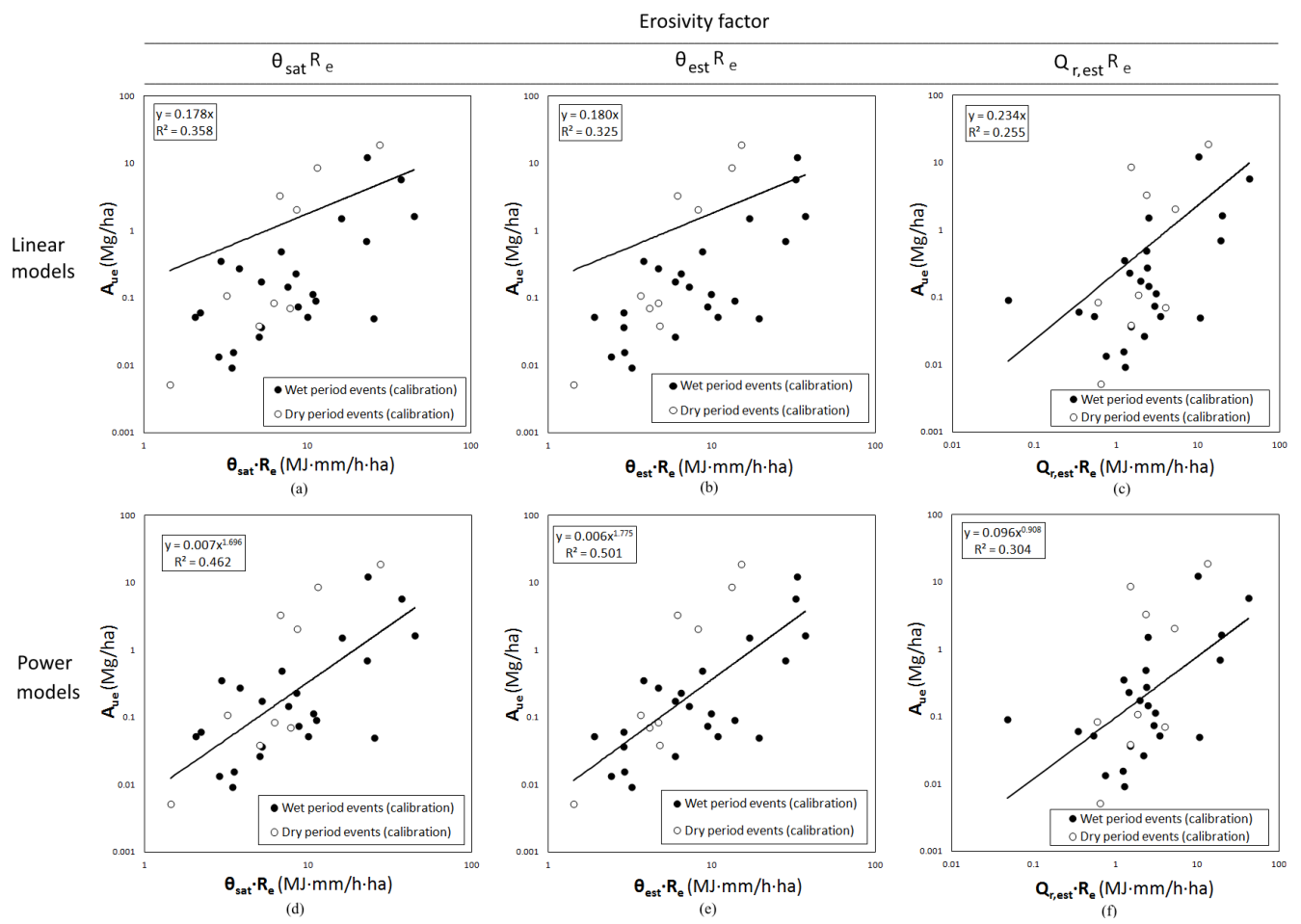

Figure 3. Regression models between measured soil loss $\mathrm{A}_{u \mathrm{e}}$ and the erosivity indices $\theta R_{\mathrm{e}}$ and $Q_{\mathrm{r}} R_{\mathrm{e}}$ of the calibration subset. Linear models (a), (b), (c): SM4E model and satellite soil moisture (a); SM4E model and estimated soil moisture (b); USLE-M model and estimated runoff coefficient (c). Power models (d), (e), (f): SM4E model and satellite soil moisture (d); SM4E model and estimated soil moisture (e); USLE-MM model and estimated runoff coefficient (f).

Table 2. Calibration parameters and validation root mean square error for the SM4E models (Eq. 4).

\begin{tabular}{llllllll}
\hline Erosivity factor & \multicolumn{3}{c}{ All the events } & \multicolumn{3}{c}{ Wet period events } \\
\cline { 2 - 8 } & RMSE $\left(\mathrm{Mg} \mathrm{ha}^{-1}\right)$ & $\mathrm{K}_{u, \theta}$ & $\alpha$ & RMSE $\left(\mathrm{Mg} \mathrm{ha}^{-1}\right)$ & $\mathrm{K}_{u, \theta}$ & $\alpha$ \\
\hline$\theta_{\text {sat }} R_{\mathrm{e}}$ & 3.07 & 0.178 & - & 1.10 & 0.174 & - \\
$\left(\theta_{\text {sat }} R_{\mathrm{e}}\right)^{\alpha}$ & 3.04 & 0.007 & 1.70 & 1.15 & 0.042 & 1.14 \\
$\theta_{\text {est }} R_{\mathrm{e}}$ & 2.85 & 0.180 & - & 1.63 & 0.270 & - \\
$\left(\theta_{\text {est }} R_{\mathrm{e}}\right)^{\alpha}$ & 2.80 & 0.006 & 1.78 & 1.26 & 0.043 & 1.29 \\
\hline
\end{tabular}

RMSE: root mean square error; $K_{u}$ : scale factor; $\alpha$ : exponent for the erosivity factor.

thermore, for model comparison, two criteria, namely Akaike information criterion (AIC, Akaike, 1974) and Bayesian information criterion (BIC, Burnham and Anderson, 2002), are used. According to these criteria the best model provides the lowest AIC and BIC values. The results show that the power model performs better than linear model.

The power model provides AIC values of 30.14 and 32.56 respectively for $\theta=\theta_{\text {est }}$ and $\theta=\theta_{\text {sat }}$, which are lower than the corresponding values, 85.41 and 83.80 , derived from the linear model, thus denoting a statistically significant better accuracy. Similarly, the BIC values for the power model, 26.47 and 28.89 , are lower than the corresponding values, 83.63 and 82.02, derived from the linear model. Moreover, according to Nagin and Roeder (2001), the difference be- tween the BIC values, 57.15 and 53.12, obtained respectively for $\theta=\theta_{\text {est }}$ and $\theta=\theta_{\text {sat }}$, can be considered significant, being greater than 10 . The models using $\left(\theta R_{\mathrm{e}}\right)^{\alpha}$ as erosivity factor (both satellite and simulated $\theta$ ) appear to work quite well. We note that the SM4E model incorporating satellite-derived soil moisture data might effectively and easily be applied over large areas for the estimation of event water soil loss.

\subsection{Comparison with the previous studies at Masse site}

The results provide a clear indication that the power models perform better than the linear models. They also show that the coefficients of determination of the USLE-derived models that include simulated or satellite-retrieved soil moisture 
in the erosivity factor (SM4E models) never exceed the value of 0.5 . This is lower than that obtained by the USLE-M and $\operatorname{USLE}-\mathrm{MM}\left(R^{2}=0.82\right)$, which include direct measurements of the runoff in the event rainfall-runoff factor (Todisco et al., 2012b). However, the benchmark for a correct assessment of the accuracy of the SM4E models is the performance of the USLE-derived models that include predicted runoff coefficient, $Q_{\mathrm{r} \text {,est }}$, in the event rainfall-runoff factor such as that analyzed by Todisco et al. (2012b). This analysis was extended to the current database. As stated earlier the runoff volumes were estimated from the calibrated rainfallrunoff model MISDc. A paired $t$ test shows that there are no significant $(\alpha=0.05)$ differences between the observed and the estimated runoff samples in both the calibration and in the validation sets. Furthermore MISDc provides fairly accurate event runoff estimates with a Nash and Sutcliffe efficiency index, NSE $=0.416$ between the $Q_{\mathrm{e} \text {,est }}$ and the observed $Q_{\mathrm{e}}$ of the calibration events and an RMSE $=2.56 \mathrm{~mm}$ and NSE $=0.450$ between the validation events.

The regressions models between the soil loss and the erosivity factor $Q_{\mathrm{r} \text {,est }} R_{\mathrm{e}}$ with $\alpha \geq 1$ (Fig. 3c and f) for the set of calibration events were derived and shown in the scatterplots of Fig. 3. The coefficient of determination using $\left(Q_{\mathrm{r}, \text { est }} \cdot R_{\mathrm{e}}\right)^{\alpha}$, $R^{2}=0.304$, is higher than that obtained with the corresponding linear model, $R^{2}=0.255$. The erosivity index $Q_{\mathrm{r}, \text { est }} R_{\mathrm{e}}$ performs better when raised to an exponent $\alpha>1$, making it possible to obtain higher coefficients of determination $R^{2}$. In all cases the coefficient of determination is slightly lower than that obtained for the corresponding SM4E models.

Furthermore both the AIC and BIC criteria show that the power model provides lower values, 40.80 and 37.13 , than the linear model, 88.57 and 86.78 , thus denoting a statistically significant better accuracy. As seen earlier, according to Nagin and Roeder (2001), the difference between the BIC values obtained, 49.65 , can be considered significant. Moreover, the AIC and BIC values associated with the USLEderived models with simulated runoff in the erosivity factors are always higher than those provided by the SM4E models, which prove to be more efficient. The accuracy of the calibrated models in estimating the event plot soil loss, $A_{u \text { e,est }}$, was tested with the validation values of $R_{\mathrm{e}}$ and $Q_{\mathrm{e} \text {,est }}$. The results are given in Fig. 4, by showing the dispersion of the $\left(A_{u \mathrm{e}}, A_{u \mathrm{e}, \text { est }}\right)$ pairs around the $1: 1$ line for the linear model (Fig. 4c) and the power model (Fig. 4f). The results in terms of RMSE obtained with the linear model are equal to $2.96 \mathrm{Mg} \mathrm{ha}^{-1}$ and remain almost constant when the power model is used. The errors are higher, even if only slightly, than those obtained with the linear SM4E and between those obtained with the two power SM4E models tested. Figure 5 also shows the comparison between the results obtained in terms of RMSE and $R^{2}$ in this study with Eq. (4), the results obtained by extending the analysis performed in Todisco et al. (2012b) to the current 63 erosive events, and the results obtained with the USLE model. Only the results of the power models compared with the USLE are shown in Fig. 5 since the power models have proven to be better than the linear models both in this study and in Todisco et al. (2012b). The accuracy in the estimation of the soil loss by the USLE-MM model that includes the predicted runoff coefficient in the event rainfall-runoff factor quantified in an RMSE $=2.96 \mathrm{Mg} \mathrm{ha}^{-1}$ is higher than that obtained with $\left(\theta_{\mathrm{est}} \cdot R_{\mathrm{e}}\right)^{\alpha}$ and slightly lower than that derived obtained with $\left(\theta_{\mathrm{sat}} \cdot R_{\mathrm{e}}\right)^{\alpha}$ (Fig. 5). The worst performance is that of the USLE model with an RMSE $=3.28 \mathrm{Mg} \mathrm{ha}^{-1}$, while the lowest coefficient of determination is obtained for the USLEMM with estimated runoff $\left(R^{2}=0.185\right)$. It is interesting to notice that the accuracy in estimating the event soil loss of the models with erosivity factor that includes the simulated runoff coefficient, i.e., $\left(Q_{\mathrm{r} \text {,est }} \cdot R_{\mathrm{e}}\right)^{\alpha}$, is overcome surpassed by at least one model that uses the antecedent soil moisture $\theta$ in the erosivity index. In Fig. 6, the deviations between observed and predicted soil loss values are also given with the corresponding runoff coefficient and the mean soil moisture (average of $\theta_{\text {est }}$ and $\theta_{\text {sat }}$ ) values. On the one hand, it is evident that the introduction of both the soil moisture and the predicted runoff coefficient data significantly reduces the overestimation issues of the USLE model. The correction is also effective when USLE highly overestimates soil losses, e.g., in May 2009 and August 2013. On the other hand, when USLE underestimates the measured values, the use of soil moisture and predicted runoff coefficient slightly increases the deviations (June and September 2010, July 2011 and August 2012). Also given in Fig. 6 is the mean absolute error (MAE), which confirms the ranking of the best performing models and clearly shows that the soil moisture is an effective alternative to estimated runoff in the prediction of the event soil loss.

\subsection{Model performance in wet and dry periods}

As stated earlier, the white dots in Figs. 3 and 4 represent the events that occurred during the dry period (from June to September). It is evident that for these events the estimated soil losses are distant from the regression line and the $1: 1$ line, thus reducing the value of $R^{2}$ and RMSE. In Fig. 6 the highest deviations between the observed and estimated values occur in the dry period events. This is likely due to the particular characteristics of summer rainfall events in central Europe (Todisco et al., 2012b; Todisco, 2014). Summer rainfall events are generally isolated and characterized by high intensity associated with low antecedent soil moisture but elevated soil losses. Therefore, even with a high $R_{\mathrm{e}}$, the erosivity factor $\theta R_{\mathrm{e}}$ is reduced since both $\theta_{\mathrm{sat}}$ and $\theta_{\mathrm{est}}$ assume typically low values. As a representative example, the event characterized by the highest soil loss $\left(A_{u \mathrm{e}}=19.14 \mathrm{Mg} \mathrm{ha}^{-1}\right.$, July 2012) is associated with the lowest pre-event soil moisture, both satellite-derived $\left(\theta_{\text {sat }}=0.09 \mathrm{~m}^{3} \mathrm{~m}^{-3}\right)$ and simulated $\left(\theta_{\text {est }}=0.05 \mathrm{~m}^{3} \mathrm{~m}^{-3}\right)$. This issue affects the $Q_{\mathrm{r}} R_{\mathrm{e}}$ erosivity factor too, if $Q_{\mathrm{r}}$ is derived from runoff simulated by standard rainfall-runoff models in which runoff increases 

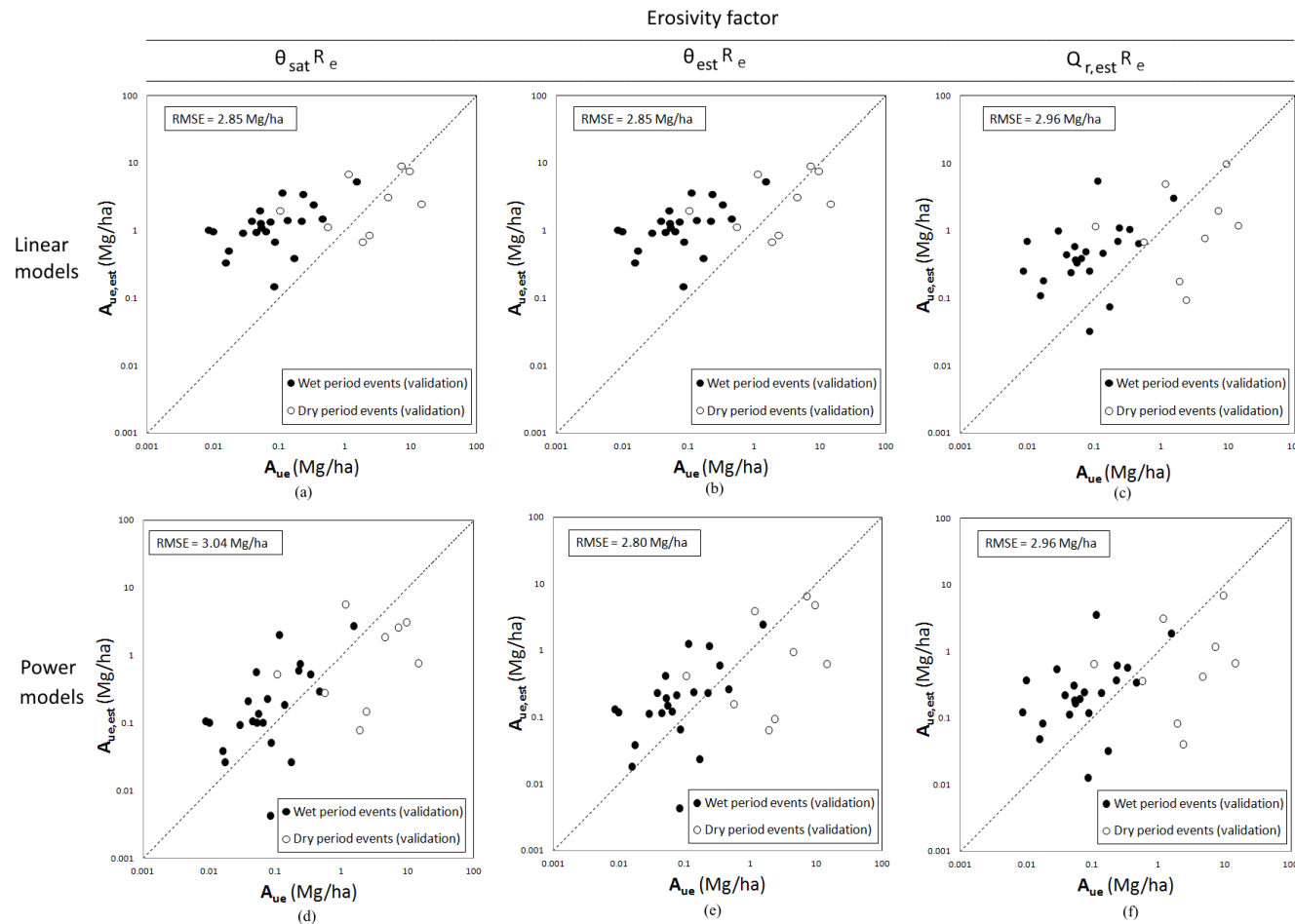

Figure 4. Testing of the $A_{u \mathrm{e}}$ vs. $\theta R_{\mathrm{e}}$ and the $\mathrm{A}_{u \mathrm{e}}$ vs. $Q_{\mathrm{r}} R_{\mathrm{e}}$ models with the validation subset. Linear models (a), (b), (c): SM4E model and satellite soil moisture (a); SM4E model and estimated soil moisture (b); USLE-M model and estimated runoff coefficient (c). Power models (d), (e), (f): SM4E model and satellite soil moisture (d); SM4E model and estimated soil moisture (e); USLE-MM model and estimated runoff coefficient (f).

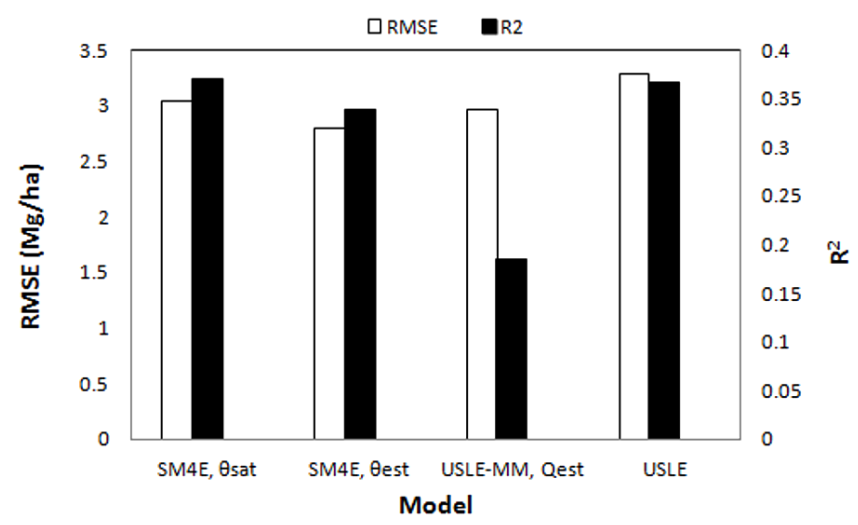

Figure 5. Comparison of the results obtained by the power SM4E model with both satellite and estimated soil moisture, the USLEMM including predicted runoff, and the original USLE, in terms of root mean square error (RMSE) and coefficient of determination $\left(R^{2}\right)$.

with antecedent soil moisture conditions (Todisco et al., $2012 b$ ). In the dry period, high surface runoff is observed, despite low $\theta$ values, due to the development of superficial crusts creating a shield that is responsible for low infiltration and high runoff. This aspect is particularly significant for bare soil as in the plots considered in this study.
Given the above consideration, another analysis was performed excluding the dry period's events from the database. Among the 45 remaining events, 23 are used to calibrate the models and 22 to validate the results. In this case, as expected, the performances of all the equations analyzed generally increase (Table 2). In particular, for the calibration subset, $R^{2}=0.247$ and $R^{2}=0.496$ are obtained for the erosivity factor $\left(\theta_{\mathrm{sat}} R_{\mathrm{e}}\right)^{\alpha}$ for $\alpha=1$ and $\alpha>1$, respectively. The $\left(\theta_{\text {est }} R_{\mathrm{e}}\right)^{\alpha}$ factor gives $R^{2}=0.605$ and $R^{2}=0.715$ for $\alpha=1$ and $\alpha>1$, respectively. Therefore, particularly the performance of the regression significantly increases in terms of $R^{2}$ especially when modeled data are used.

In validation, $\mathrm{RMSE}=1.10 \mathrm{Mg} \mathrm{ha}^{-1}\left(1.15 \mathrm{Mg} \mathrm{ha}^{-1}\right)$ is obtained with satellite soil moisture with the linear (power) model; by using modeled soil moisture, the linear model gives $\mathrm{RMSE}=1.63 \mathrm{Mg} \mathrm{ha}^{-1}$, while the power model gives $\mathrm{RMSE}=1.26 \mathrm{Mg} \mathrm{ha}^{-1}$ (see Table 2). In comparison, the USLE model provides an RMSE $=1.99 \mathrm{Mg} \mathrm{ha}^{-1}$; thus the modified-USLE model moisture data - the SM4E models improved the performance of the USLE when satellite (modeled) data were considered. 


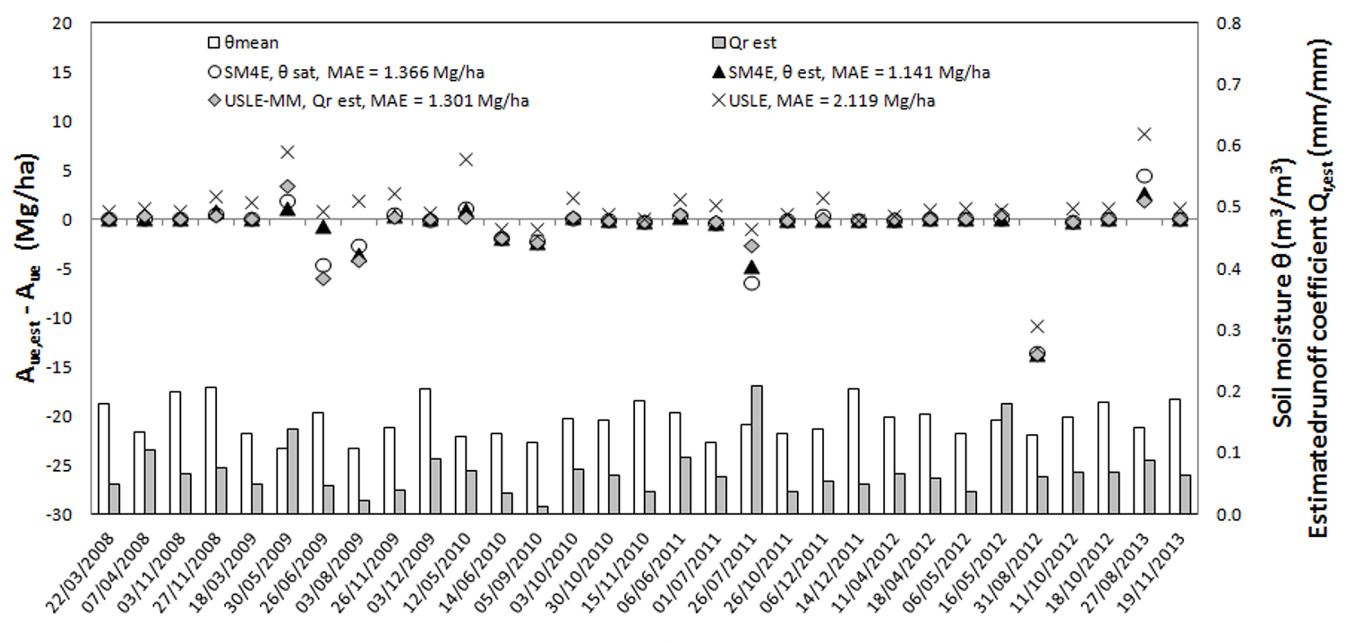

Figure 6. Comparison of the results obtained by the power SM4E model with both satellite and estimated soil moisture, the USLE-MM including predicted runoff, and the original USLE, in terms of deviations between estimated, $A_{u \text { e, est }}$, and observed, $A_{u \text { e }}$, soil losses. The values of the estimated runoff and of the mean soil moisture computed as the mean between the estimated and the satellite-retrieved values are also given.

\section{Conclusions}

The attempt made in the paper is to use the pre-event soil moisture to account for the spatial variation in runoff within the area for which the soil loss estimates are required. More specifically the analysis was focused on the evaluation of the effectiveness of the Soil Moisture for Erosion model (SM4E), which is derived by coupling modeled or satellitederived soil moisture with the USLE model, in predicting event unit soil loss at the plot scale in a silty-clay-loam soil in central Italy. To this end, the Masse experimental station database for the measurement of event soil losses at plot scale was used.

The formulations analyzed are the USLE-derived equations, called SM4E models, in which the event erosivity factor, $R_{\mathrm{e}}$, is corrected by the antecedent soil moisture, $\theta$, and powered to an exponent $\alpha \geq 1$ ( $\alpha=1$ : linear model; $\alpha>1$ : power model). Both satellite measurements from the ASCAT sensor $\left(\theta=\theta_{\text {sat }}\right)$ and modeled values through the SWBM $\left(\theta=\theta_{\text {est }}\right)$ were tested. The results showed that including direct consideration of antecedent soil moisture in the event rainfall-runoff erosivity factor of the USLE enhanced the capacity of the model to account for variations in event soil losses.

The accuracy of the original USLE model was lower than that obtained by incorporating satellite and modeled soil moisture data. The most accurate model is that with the modeled soil moisture data when the entire the database is used and with the satellite-retrieved soil moisture data when only the wet period events are considered. It was in fact also verified that much of the inaccuracy of the tested models is due to summer rainfall events, probably because of the particular characteristics that the soil assumes in the dry period (superficial crusts causing higher runoff): in these cases, high soil losses are observed in association with low soil moisture values, and, hence, the model performance decreases. As expected, by excluding the summer events, the performance of all the analyzed equations increases. This aspect is particularly important, as it highlights the conditions in which the developed models fail to reproduce soil losses and that deserves further investigation. More specifically, the incorporation of the mechanism for the formation of superficial crusts in the developed soil water balance model will be the subject of future investigations.

We highlight that the obtained results open interesting scenarios in the overview of the studies aimed at defining USLEderived models that could improve the unit soil loss estimation at the event scale. In particular, the choice of using soil moisture data to correct the rainfall-runoff erosivity factor takes on great importance for the practice. Indeed, soil moisture is a relatively simple measurement, and different techniques are available for providing accurate measurements at the field scale. Moreover, remote sensing soil moisture data are also widely available on a global scale. Through satellite data, there is the potential of applying the developed USLEderived model for large-scale monitoring and quantification of the soil erosion process.

Acknowledgements. This research was financially supported by the PRIN 2010-2011 Project (B71J12000610001). Funding by EUMESAT through the "Satellite Application Facility on Support to Operational Hydrology and Water Management (H-SAF)" project is also gratefully acknowledged. 
Edited by: D. Mazvimavi

\section{References}

Akaike, H.: New look at the statistical model identification, IEEE Transactions on Automatic Control, AC-19, 716-723, 1974.

Bagarello, V. and Ferro, V.: Plot-scale measurement of soil erosion at the experimental area of Sparacia (southern Italy), Hydrol. Process., 18, 141-157, 2004.

Bagarello, V., Di Piazza, G. V., Ferro, V., and Giordano, G.: Predicting unit soil loss in Sicily, south Italy, Hydrol. Process., 22, 586-595, 2008.

Bagarello, V., Ferro, V., and Giordano, G.: Testing alternative erosivity indices to predict event soil loss from bare plots in southern Italy, Hydrol. Process., 24, 789-797, 2010.

Bagarello, V., Di Stefano, C., Ferro, V., Kinnell, P. I. A., Pampalone, V., Porto, P., and Todisco, F.: Predicting soil loss on moderate scope using an empirical model for sediment concentration, J. Hydrol., 400, 267-273, 2011.

Bagarello, V., Di Stefano, C., Ferro, V., Giordano, G., Iovino, M., and Pampalone, V.: Estimating the USLE soil erodibility factor in Sicily, south Italy, Appl. Eng. Agric., 28, 199-206, 2012.

Bagarello, V., Ferro, V., Giordano, G., Mannocchi, F., Todisco, F., and Vergni, L.: Predicting event soil loss form bare plots at two Italian sites, Catena, 109, 96-102, 2013.

Bagarello, V., Ferro, V., and Pampalone, V.: Testing assumptions and procedures to empirically predict bare plot soil loss in a Mediterranean environment, Hydrol. Process., doi:10.1002/hyp.10382, 2014.

Brocca, L., Melone, F., and Moramarco, T.: On the estimation of antecedent wetness conditions in rainfall-runoff modelling, Hydrol. Process., 22, 629-642, 2008.

Brocca, L., Melone, F., Moramarco, T., and Singh, V. P.: Assimilation of observed soil moisture data in storm rainfall-runoff modelling, J. Hydrol. Eng., 14, 153-165, 2009.

Brocca, L., Melone, F., Moramarco, T., Wagner, W., and Hasenauer, S.: ASCAT Soil Wetness Index validation through in-situ and modeled soil moisture data in central Italy, Remote Sens. Environ., 114, 2745-2755, 2010.

Brocca, L., Melone, F., and Moramarco, T.: Distributed rainfallrunoff modeling for flood frequency estimation and flood forecastig, Hydrol. Process., 25, 2801-2813, 2011 a.

Brocca, L., Hasenauer, S., Lacava, T., Melone, F., Moramarco, T., Wagner, W., Dorigo, W., Matgen, P., Martínez-Fernández, J., Llorens, P., Latron, J., Martin, C., and Bittelli, M.: Soil moisture estimation through ASCAT and AMSR-E sensors: an intercomparison and validation study across Europe, Remote Sens. Environ,, 115, 3390-3408, 2011 b.

Brocca, L., Ponziani, F., Moramarco, T., Melone, F., Berni, N., and Wagner, W.: Improving landslide forecasting using ASCATderived soil moisture data: A case study of the Torgiovannetto landslide in central Italy, Remote Sens., 4, 1232-1244, 2012.

Brocca, L., Zucco, G., Moramarco, T., and Morbidelli, R.: Developing and testing a long-term soil moisture dataset at the catchment scale, J. Hydrol., 490, 144-151, 2013.

Brocca, L., Zucco, G., Mittelbach, H., Moramarco, T., and Seneviratne, S. I.: Absolute versus temporal anomaly and percent of saturation soil moisture spatial variability for six networks worldwide, Water Resour. Res., 50, 5560-5576, 2014a.

Brocca, L., Camici, S., Melone, F., Moramarco, T., MartinezFernandez, J., Didon-Lescot, J.-F., and Morbidelli, R.: Improving the representation of soil moisture by using a semi-analytical infiltration model, Hydrol. Process., 28, 2103-2115, 2014b.

Burnham, K. P. and Anderson, D. R.: Model Selection and Multimodel Inference: A Practical Information-Theoretic Approach, Springer New York, 284-288, 2002.

Butzen, V., Seeger, M., Wirtz, S., Huemann, M., Mueller, C., Casper, M., and Ries, J. B.: Quantification of Hortonian overland flow generation and soil erosion in a Central European low mountain range using rainfall experiments, Catena, 113, 202212, 2014.

Cerdà, A.: The influence of aspect and vegetation on seasonalchanges in erosion under rainfall simulation on a clay soil in Spain, Can. J. Soil Sci., 78, 321-330, 1998.

Di Stefano, C., Ferro, V., and Minacapilli, M.: Testing the SEDD model in Sicilian basins IAHS Publ., 292, 152-161, 2005.

Doorenbos, J. and Pruitt, W. O.: Background and development of methods to predict reference crop evapotranspiration (ETo), FAO-ID-24, Appendix II, 108-119, 1977.

Famiglietti, J. S. and Wood, E. F.: Multiscale modeling of spatially variable water and energy balance processes, Water Resour. Res., 11, 3061-3078, 1994.

Flanagan, D. C., Gilley, J. E., and Franti, T. G.: Water erosion prediction project (WEPP): development history, model capabilities and future enhancements, T. ASABE, 50, 1603-1612, 1995.

Foster, G. R., Lombardi, F., and Moldenhauer, W. C.: Evaluation of rainfall-runoff erosivity factors for individual storms, T. ASAE, 25, 124-129, 1982.

Foster, G. R., Toy, T. E., and Renard, K. G.: Comparison of the USLE, RUSLE1.06 and RUSLE2 for application to highly disturbed lands, edited by: Renard, K. G., Mc Ilroy, S. A., Gburek, W. J., Cranfield, H. E., and Scott, R. L., in: First Interagency Conference on Research in Watersheds, October 27-30, USDA, 2003.

Gao, G. Y., Fu, B. J., Lü, Y. H., Liu, Y., Wang, S., and Zhou, J.: Coupling the modified SCS-CN and RUSLE models to simulate hydrological effects of restoring vegetation in the Loess Plateau of China, Hydrol. Earth Syst. Sci., 16, 2347-2364, doi:10.5194/hess-16-2347-2012, 2012.

Huang, C.: Sediment regimes under different slope and surface hydrologic conditions, Soil Sci. Soc. Am. J., 62, 423-430, 1998.

Kinnell, P. I. A.: Runoff ratio as a factor in the empirical modeling of soil erosion by individual rainstorms, Aus. J. Soil Res., 35, 1-13, 1997.

Kinnell P. I. A.: Runoff dependent erosivity and slope length factors suitable for modeling annual erosion using the Universal Soil Loss Equation, Hydrol. Process. 21, 2681-2689, 2007.

Kinnell, P. I. A.: Event soil loss, runoff and the Universal Soil Loss Equation family of models: A review, J. Hydrol., 385, 384-397, 2010.

Kinnell, P. I. A.: Modelling event soil losses using QREI30 index with RUSLE2, Hydrol. Process., 28, 2761-2771, 2014.

Kinnell, P. I. A.: Accounting for the influence of runoff on event soil erodibilities associated with the $\mathrm{EI}_{30}$ index in RUSLE2, Hydrol. Process., 29, 1397-1405, 2015. 
Kinnell, P. I. A. and Risse, L. M.: USLE-M: empirical modeling rainfall erosion through runoff and sediment concentration, Soil Sci. Soc. Am. J., 62, 1667-1672, 1998.

Lacava, T., Matgen, P., Brocca, L., Bittelli, M., and Moramarco, T.: A first assessment of the SMOS soil moisture product with insitu and modelled data in Italy and Luxembourg, IEEE Trans. Geosci. Remote Sens., 50, 1612-1622, 2012.

Larson, W. E., Lindstrom, M. J., and Schumacher, T. E.: The role of severe storms in soil erosion: a problem needing consideration, J. Soil Water Conserv., 52, 90-95, 1997.

Leh, M., Bajwa, S., and Chaubey, I.: Impact of land use change on erosion risk: an integrated remote sensing geopraphic information system and modeling methodology, Land Degrad. Develop., 24, 409-421, 2013.

Ligonja, P. J. and Shrestha, R. P.: Soil erosion assessment in Kondoa eroded area in Tanzania using Universal Soil Loss Equation, geographic information systems and socioeconomic approach, Land Degrad. Develop., doi:10.1002/ldr.2215, 2013.

Mannocchi, F., Todisco, F., Vergni, L., and Vinci, A.: Calibrazione di un sistema di misura di erosione idrica a scala di parcella, in: Atti del $31^{\circ}$ Convegno Nazionale di Idraulica e Costruzioni Idrauliche, Morlacchi Editore, Perugia, 1-8, 2008.

Morgan, R. P. C.: Soil Erosion and Conservation, Blackwell Publishing, Malden, MA, USA, 3rd edition, 2005.

Morgan, R. P. C. and Nearing, M. A.: Soil erosion models: present and future, in: Proceedings of the Third International Congress "Man and Soil at the Third Millennium", edited by: Rubio, J. L., Asins, S., Andreu, V., de Paz, J. M., and Gimeno, E., European Society for Soil Conservation, Valencia, Spain, 28 March-1 April, 145-164, 2000.

Nagin, J. B. and Roeder, K. A.: SAS procedure based on mixture models for estimating developmental trajectories. Sociol. Meth. Res., 29, 374-393, 2001.

Nearing, M. A.: A single continuous function for slope steepness influence on soil loss, Soil Sci. Soc. Am. J., 61, 917-919, 1997.

Parsons, A. J., Brazier, R. E., Wainwright, J., and Powell, D. M.: Scale relationships in hillslope runoff and erosion, Earth Surf. Process. Landf., 31, 1384-1393, 2006.

Porto, P., Walling, D. E., and Capra A., Using ${ }^{137} \mathrm{Cs}$ and ${ }^{210} \mathrm{~Pb}_{\mathrm{ex}}$ measurements and conventional surveys to investigate the relative contributions of interrill/rill and gully erosion to soil loss from a small cultivated catchment in Sicily, Soil Tillage Res., 135, 18-27, 2014.

Rejman, J., Usowicz, B., and Dçbicki, R.: Source of errors in predicting silt soil erodibility withusle, Pol. J. Soil Sci., 32, 20-22, 1999.

Renard, K. G., Foster, G. R., Weesies, G. A., McCool, D. K., and Ynder, D. C.: Predicitng Soil Erosion By Water: A Guide To Conservationvation Planning With the Revised Universal Soil Loss Equation (RUSLE). United States Department of Agriculture-USDA. Agriculture Handbook Number 703, Washington, D.C., USA, 1997.

Risse, L. M., Nearing, M. A., Nicks, A. D., and Laflen, J. M.: Error assessment in the Universal Soil Loss Equation, Soil Sci. Soc. Am. J., 57, 825-833, 1993.
Soil Survey Staff: Keys to Soil Taxonomy, USDA-Natural Resources Conservation Service, Washington, DC, USA, 10th edition, 2006.

Tiwari, A. K., Risse, L. M., and Nearing, M.: Evaluation of WEPP and its comparison with USLE and RUSLE, T. ASAE, 43, 1129 $1135,2000$.

Todisco, F.: The internal structure of erosive and non-erosive storm events for interpretation of erosive processes and rainfall simulation, J. Hydrol., 519, 3651-3663, 2014.

Todisco, F., Mannocchi, F., Vergni, L, and Vinci A.: Plot scale measurements of rainfall erosion losses in central Italy, IAHS Publ., 327, 324-330, 2009.

Todisco, F., Vergni, L., Mannocchi, F., and Bomba, C.: Calibration of the soil loss measurement at the Masse experimental station, Catena, 91, 4-9, 2012a.

Todisco, F., Brocca, L., Mannocchi, F., Melone, F., and Moramarco, T.: Utilizzo di modellistica idrologica in continuo accoppiata ad un modello USLE modificato per la previsione della perdita di suolo parcellare in Umbria, Quaderni di Idronomia Montana, 30, 353-362, 2012b.

Vrieling, A., Hoedjes, J. C. B., and van der Velde, M.: Towards large-scale monitoring of soil erosion in Africa: Accounting for the dynamics of rainfall erosivity, Glob. Planet. Change, 115, 33 43, 2014.

Wagner, W., Lemoine, G., and Rott, H.: A method for estimating soil moisture from ERS scatterometer and soil data, Remote Sens. Environ., 70, 191-207, 1999.

Wagner, W., Hahn, S., Kidd, R., Melzer, T., Bartalis, Z., Hasenauer, S., Figa, J., de Rosnay, P., Jann, A., Schneider, S., Komma, J., Kubu, G., Brugger, K., Aubrecht, C., Zuger, J., Gangkofner, U., Kienberger, S., Brocca, L., Wang, Y., Bloeschl, G., Eitzinger, J., Steinnocher, K., Zeil, P., and Rubel, F: The ASCAT Soil Moisture Product: A Review of its Specifications, Validation Results, and Emerging Applications, Meteorol. Z., 22, 5-33, 2013.

Williams, J. R.: Sediment-yield prediction with universal equation using runoff energy factor. in: Present and Prospective Technology for Predicting Sediment Yield and Sources, USDA, Washington, DC, USA, 244-252, 1975.

Williams, J. R. and Berndt, H. D.: Sediment yield prediction based on watershed hydrology, T. ASAE, 20, 1100-1104, 1977.

Williams, J. R., Jones, C. A., and Dyke, P. T.:. A modeling approach to determining the relationship between erosion and productivity, T. ASAE, 27, 129-144, 1984a.

Williams, J. R., Jones, C. A., and Dyke, P. T.: The EPIC model and its application, in: Proceedings of the International Symposium on minimum data sets for agrotechnology transfer, 21-26 March, 1983, ICRISAT Center, India, 1984b.

Williams, J. W., Izaurralde, R. C., and Steglich, E. M.: Agricultural Policy/Environmental Extender model theoretical documentation, BRC Report \#2008-17, Blackland Research and Extension Center, Temple, TX, USA, 2008.

Wischmeier, W. H. and Smith, D. D.: Predicting rainfall-erosion losses - A guide to conservation planning, Agric. Handb. 537, USDA, 1978. 